\title{
A INDÚSTRIA DOS JOGOS ELETRÔNICOS: NOVAS TECNOLOGIAS, PROPRIEDADE INTELECTUAL E CENÁRIO MUNDIAL E BRASILEIRO
}

\author{
Carolina Brasil Romão e Silva ${ }^{1}$
}

Resumo: O presente artigo tem como objetivo identificar características da indústria de jogos eletrônicos, tendo em vista o crescimento considerável do valor do mercado mundial de jogos eletrônicos nos últimos anos. A evolução da tecnologia tem permitido o surgimento de novos setores como o setor de jogos. Este setor tem possibilitado a disponibilização de entretenimento, principalmente com o advento da internet e da plataforma online. Assim, analisa-se como o surgimento de novas tecnologias possibilitaram novos modelos de negócio e o desenvolvimento do setor de jogos eletrônicos. Verifica-se como a transformação na economia global interfere na gestão de propriedade intelectual. Examina-se a importância da propriedade intelectual no setor de jogos eletrônicos, tendo em vista que os jogos possuem dois elementos essenciais: o programa de computador, além de elementos individuais (ou seja, os personagens, sua trilha sonora, configurações, etc.), que podem ser protegidos por direitos autorais. Nesta seara, verifica-se que não existe uma classificação explícita para jogos eletrônicos nos termos da legislação brasileira, assim há a opção por um regime no qual é possível a proteção nestas duas esferas (direito autoral e programa de computador). Neste sentido, os elementos audiovisuais dos jogos eletrônicos podem ser enquadrados na definição da Lei de Direito Autoral de obra audiovisual (art. 50, VIII, "i" da Lei 9.610/1996) e o programa de computador seria protegido pela Lei $\mathrm{n}^{\circ} 9.279$, de 14 de maio de 1996. Ademais, identificam-se o cenário mundial e brasileiro da indústria de jogos eletrônicos, tendo em vista o crescimento considerável do valor do mercado mundial de jogos eletrônicos nos últimos anos.

Palavras-chaves: Indústria de jogos eletrônicos; era digital, propriedade intelectual; modelos de negócios.

Abstract: This paper aims to identify characteristics of the electronic game industry, in view of the considerable growth of the value of the worldwide market of electronic games in recent years. The evolution of technology has allowed the emergence of new sectors such as the gaming industry. This sector has made possible the availability of entertainment especially with the advent of the internet and the platform online. It is analyzed how the globalization of innovation and the emergence of new technologies have enabled new business models and the development of the electronic games industry. It turns out how the transformation in the global economy interferes in the management of intellectual property.The importance of intellectual property in the games industry is examined, considering that the games have two essential elements: the computer program, in addition to individual elements (ie, characters, their soundtrack, settings, etc.), which may be protected by author's right. In this section, it is verified that there is no explicit classification for electronic games under Brazilian law, so there is the option for a regime in which it is possible to protect in these two spheres (copyright and computer program). In this sense, the audiovisual elements of the electronic games can be included in the definition of the author

\footnotetext{
1* Carolina Brasil Romão e Silva é doutoranda em Propriedade Intelectual e Inovação pelo Instituto Nacional da Propriedade Industrial - INPI. Mestre em Direito e Políticas Públicas pela Universidade Federal do Estado do Rio de Janeiro - UNIRIO. Formada em Direito pela Universidade do Estado do Rio de Janeiro -UERJ, pósgraduada em Gestão Pública pela Universidade Cândido Mendes. Especialista em Regulação na Agência Nacional do Cinema - ANCINE email: carolinabrasil2@hotmail.com.
} 
right's Law of audiovisual works (article 5, VIII, "i" of Law 9.610 / 1996) and computer program would be protected by Law 9,279, of May 14, 1996. In addition, the world and Brazilian scenario of electronic games industry are identified, in view of the considerable growth of the value of the world market of electronic games in recent years.

Keywords: Games industry; digital era; intellectual property; business models.

\section{INTRODUÇÃO}

Com o progresso científico, os autores conseguiram aperfeiçoar suas obras de arte usando novas ferramentas, além de melhores técnicas. Esta evolução eventualmente possibilitou a criação de novas obras de autoria, como obras cinematográficas e, mais recentemente, jogos eletrônicos (OMPI, 2013).

Os jogos eletrônicos são obras complexas de autoria - contendo múltiplas formas de arte, como música, scripts, gráficos, vídeos, pinturas e personagens - que envolvem interação humana ao executar o jogo com um programa de computador em hardware específico.

Assim, os jogos eletrônicos são criações complexas com uma amalgama de elementos individuais que podem ser protegidos por direitos autorais, como os personagens, sua trilha sonora, configurações, se eles alcançarem um certo nível de originalidade e criatividade.

Existem vários gêneros de jogos eletrônicos, incluindo jogos de ação, jogos de açãoaventura, jogos de aventura, jogos de role-playing, jogos de simulação, jogos de estratégia, jogos de música, jogos de festa, jogos esportivos e jogos triviais. Os elementos constituintes de cada tipo de jogo - e, mais precisamente, dentro de cada jogo específico - variam. No entanto, todos estes jogos compartilham um elemento comum: o programa de computador que executa o jogo.

A indústria de jogos eletrônicos é um setor econômico que se refere à indústria de entretenimento interativo ou à indústria de entretenimento digital, e está relacionado ao desenvolvimento, marketing e vendas de jogos eletrônicos. De acordo com a OCDE, esperase que o setor de mídia digital se torne um dos principais setores do futuro (OCDE, 2005).

A indústria de jogos eletrônicos enseja inovação tecnológica e impulsiona o desenvolvimento de outros segmentos de mercado. Em sua etapa de produção, os jogos combinam a aplicação de conhecimento tecnológico e científico, além de atividades de pesquisa e expressões artísticas. Ademais, os recentes avanços tecnológicos, por exemplo a 
expansão da Internet e da banda larga móvel, o aumento da capacidade gráfica e de processamento dos hardwares proporcionaram um crescimento significativo deste mercado. Tendo sua origem no desenvolvimento da tecnologia de computadores e informática, os jogos eletrônicos, ou simplesmente games, estão em constante evolução.

O objetivo deste artigo é apresentar o setor de jogos no Brasil e no mundo e o modo e o papel da propriedade intelectual - PI neste setor. Pretende-se então identificar o cenário mundial e brasileiro da indústria de jogos eletrônicos, uma vez que este é um dos segmentos da indústria do entretenimento que mais cresce no mundo, atualmente.

Deste modo, dividiu-se este artigo em partes, em primeiro lugar se observa como a o surgimento de novas tecnologias possibilitaram novos modelos de negócio e o desenvolvimento do setor de jogos eletrônicos. Verifica-se ainda como a transformação na economia global interfere na gestão de propriedade intelectual.

Em seguida, examina-se os elementos essenciais presentes em um jogo eletrônico: o programa de computador, que é protegido pela Lei de Programa de Computador (Lei $\mathrm{n}^{\mathbf{o}}$ 9.279, de 14 de maio de 1996), além de elementos individuais (os personagens, sua trilha sonora, configurações), que podem ser individualmente protegidos por direitos autorais através da Lei nº. 9.610, de 19 de fevereiro de 1998.

Na terceira parte, destaca-se a tutela jurídica e importância da proteção dos direitos de propriedade intelectual no setor de games, considerando que o mercado de jogos eletrônicos é imaterial. Deste modo, a estrutura jurídica para administrar as relações desta indústria se localiza em grande medida no âmbito do ramo da propriedade intelectual.

Na quarta parte, realiza-se um quadro acerca do crescimento mundial da indústria de jogos eletrônicos, com base nos dados da PricewaterhouseCoopers (2015) e Newzoo (2016). Analisam-se ainda os dados obtidos através do $1^{\circ}$ Censo da Indústria Brasileira de Jogos Digitais (2014), realizado pelo Grupo de Estudos e Desenvolvimento da Indústria de Games - GEDIGames e pelo Núcleo de Política e Gestão Tecnológica - NPGT da Universidade de São Paulo - USP quanto ao cenário brasileiro da indústria de jogos eletrônicos, em especial em relação ao porte das empresas brasileiras neste setor. Por fim, concluem-se os itens discutidos.

Para isto, utiliza-se como metodologia uma revisão bibliográfica relativa ao papel da propriedade intelectual na apropriabilidade e no setor de games no Brasil e no mundo. 
1 - APROPRIABILIDADE, PROPRIEDADE INTELECTUAL E NOVAS TECNOLOGIAS

A aplicação econômica de novas ideias e conhecimentos não é apenas "técnica", na medida em que também pode ser organizacional, gerencial, institucional. As novas tecnologias intensificam a interface ciência-tecnologia e estão intrinsecamente associadas aos processos complexos de mudanças organizacionais, institucionais e de infraestrutura (FREEMAN, 1994).

O surgimento de inovações individuais não é aleatório. As tecnologias se interligam e tendem a aparecer com outras inovações. Nem a sua evolução ocorre de forma isolada. A inovação é um processo coletivo que envolve cada vez mais outros agentes de mudança: fornecedores, distribuidores, incluindo consumidores. Além disso, as principais inovações são indutoras de novas inovações, além de exigirem complementares a montante e a jusante e facilitam outros semelhantes, incluindo alternativas concorrentes (PEREZ, 2009).

Assim, as novas tecnologias desempenham um papel fundamental para tornar possível a globalização. A chegada de uma sociedade baseada no conhecimento prosseguiu juntamente com o alargamento dos mercados e a intensificação da troca (ARCHIBUGUI, D.; IAMMARINO, S.,2002).

Schumpeter (1961) defende a inovação e não a livre concorrência como grande valor do sistema capitalista e articula que a concorrência perfeita pode, inclusive, não ser desejável, posto que pressiona os preços para baixo e diminui o lucro.

A estratégia de negócios, particularmente em relação à decisão da empresa de se integrar e colaborar, é um fator importante, bem como o papel dos ativos complementares como marketing e publicidade. Em particular, os regimes de apropriabilidade de pequenas e médias empresas para invenções inovadoras são cruciais para a sobrevivência sustentável delas em longo prazo.

Observa-se que o desenvolvimento de dispositivos tecnológicos, a construção e implantação de ativos intangíveis e os ecossistemas de modelagem exigem acesso a complementos e, muitas vezes, de propriedade.

Ademais, os regimes de apropriação mudam ao longo do tempo e o regime aplicável a uma dada inovação pode ser influenciado pelas empresas. Ao considerar as estratégias de 
propriedade intelectual - PI, as empresas precisam pesar os benefícios da proteção de PI contra seus custos. A prossecução de uma estratégia de PI cara pode ser justificada pelas tecnologias subjacentes a uma competência básica, mas pode gerar altos riscos estratégicos ou de outra forma são críticas para a vantagem competitiva da empresa. No entanto, também deve ser reconhecido que uma empresa pode desejar a liberdade de projetar e inovar sem ser limitada pela PI- ou provavelmente pertencentes ao futuro - por outros.

Os elementos da estratégia, que compõem os modelos de negócios, decisões de tempo, posicionamento em ativos complementares - influenciam a vantagem competitiva do inovador e os resultados competitivos. No entanto, também é importante compreender não apenas como a PI funciona em conjunto com outros fatores para moldar os resultados do mercado. Também é importante entender como vários tipos de PI, em especial segredos comerciais, marcas e direito autoral, interagem para moldar os resultados.

Os mecanismos jurídicos de proteção da propriedade intelectual, que variam dependendo da tecnologia e de acordo com o país, contribuem na apropriação do conhecimento. Um dos elementos no processo de apropriabilidade é o direito de propriedade intelectual.

Neste sentido, Barbosa (2010) dispõe que a propriedade intelectual compreende: (i) os direitos autorais; (ii) o direito de propriedade industrial; e (iii) outros direitos sobre bens imateriais de vários gêneros (direitos sui generis). A proteção sui generis abrange: a) topografias de circuitos integrados; b) as cultivares; c) conhecimentos tradicionais ${ }^{2}$.

Segundo as normas estabelecidas pela OMPI - Organização Mundial da Propriedade Intelectual $^{3}$ - a propriedade intelectual abrange duas grandes áreas: propriedade industrial (patentes, marcas, desenho industrial, indicações geográficas e proteção de cultivares) e direito autoral (como obras literárias e artísticas e programas de computador).

Os direitos autorais são aqueles que dizem respeito às criações de caráter intelectual, artístico ou literário do espírito humano, tendo como principal atribuição a garantia de

\footnotetext{
${ }^{2}$ http://www.inpi.gov.br/sobre/arquivos/guia docente iel-senai-e-inpi.pdf. Acesso em 10/09/2017.

3 Em inglês WIPO - World Intellectual Property Organization. Segundo definição obtida no Portal do INPI - Instituto Nacional de Propriedade Industrial - a OMPI, criada em 1967, é um dos 16 organismos especializados do sistema das Nações Unidas, de caráter intergovernamental, com sede em Genebra, Suíça. Sua função consiste em: 1. Estimular a proteção da Propriedade Intelectual em todo o mundo mediante a cooperação entre os Estados; 2. Assegurar a cooperação administrativa entre as Uniões de propriedade intele ctual. 3. Estabelecer e estimular medidas apropriadas para promover, a atividade intelectual criativa e facilitar a transmissão de tecnologia relativa à propriedade industrial para os países em desenvolvimento em vista de acelerar o desenvolvimento econômico, social e cultural. Disponível em: http://www.wipo.int/portal/en/index.html.
} 


\section{A INDÚSTRIA DOS JOGOS ELETRÔNICOS: NOVAS TECNOLOGIAS, PROPRIEDADE INTELECTUAL E CENÁRIO MUNDIAL E BRASILEIRO}

proteção aos autores de eventual uso incorreto ou irresponsável feito por terceiros de suas obras, além de permitir a aqueles explorar tais obras da maneira que achar mais conveniente ${ }^{4}$.

O direito autoral compreende: a) direitos de autor que, por sua vez, abrange: obras literárias, artísticas e científicas; programas de computador; descobertas científicas. b) direitos conexos, abrangem as interpretações dos artistas intérpretes e as execuções dos artistas executantes, os fonogramas e as emissões de radiodifusão.

Os direitos de propriedade industrial visam proteger os produtos ou serviços que estão diretamente relacionados com as invenções ou marcas, além de garantir ao seu titular a possibilidade de explorá-las economicamente ou de impedir que terceiros o façam sem a sua autorização ${ }^{5}$.

A propriedade industrial abrange: a) patentes que protegem as invenções em todos os domínios da atividade humana; b) marcas, nomes e designações empresariais; c) desenhos e modelos industriais; d) indicações geográficas; e) segredo industrial e repressão à concorrência desleal (INPI, 2010).

O direito de propriedade intelectual é um instrumento de proteção e difusão do conhecimento utilizado pelos agentes do processo, conforme o desenho do modelo de negócio dos agentes econômicos (TERUYA, 2015).

A conformidade do sistema de propriedade intelectual é um instrumento na tomada de decisão dos agentes econômicos para a apropriabilidade, uma vez que os agentes econômicos buscam uma taxa de lucratividade dos investimentos realizados (TEECE, 1986).

Assim, o regime de apropriabilidade está associado com a natureza da tecnologia e a eficácia do marco regulatório para a apropriabilidade dos lucros. A natureza da tecnologia está relacionada à combinação de conhecimentos tácitos e explícitos no desenvolvimento de uma determinada solução. Um outro aspecto desse regime está relacionado com o aspecto institucional, como Direito de Propriedade Intelectual, que dá suporte às tomadas de decisões dos agentes econômicos (TERUYA, 2015).

Como ressaltado por Dosi et al. (1994), a difusão de inovações não é instantânea, e depende da heterogeneidade entre os agentes, da infraestrutura adequada para a assimilação tecnológica, e de tempo para aprender a dominar novas tecnologias. Diversos estudos visam

\footnotetext{
${ }^{4}$ Manual de Propriedade Intelectual, Diego Perez Almeida, Isabela Guimarães Del Monde, Patricia Peck Pinheiro (Coord.), 2013, UNESP.

${ }^{5}$ http://www.inpi.gov.br/sobre/arquivos/guia_docente_iel-senai-e-inpi.pdf
} 
analisar quais tipos de apropriação são mais relevantes na determinação do desempenho das firmas, comparando os métodos formais e estratégicos. Portanto, o uso dos métodos de apropriabilidade difere de acordo com os setores, especificidades tecnológicas e também dependem do comportamento estratégico das empresas (ZUCOLOTO, 2013).

Verifica-se, então, que a integração de PI e estratégia é complexa, porque se depara com barreiras de entrada, custos de transação e barreiras organizacionais. Uma estratégia de PI integrada também requer um profundo conhecimento de outros domínios. Se a estratégia e a PI estiverem integradas, a estratégia (incluindo o design do modelo de negócios) deve passar por uma auditoria proativa de PI. Assim, o elemento de gerenciamento estratégico mais sensível à disponibilidade de proteção de PI forte é o design do modelo de negócios.

O gerenciamento de PI geralmente é tratado em conjunto com outros tópicos, como as opções de modelo de negócios, capturando valor (lucrando com a inovação) ou com preocupações sobre apropriabilidade. Observa-se que uma estratégia de PI integrada deve ser consistente em todas as jurisdições em relação à política pública.

Deste modo, a transformação na economia global resultou na necessidade da gestão integrada da PI, especialmente em razão do surgimento da internet, que possibilitou novas opções de modelo de negócios, e permitiu novos métodos para distribuir conteúdo digital (por exemplo, games e música) e desvendou modelos tradicionais de cobrança para ele (por exemplo, venda de fitas, discos compactos e discos de vinil).

A chamada "Nova Economia" compreende mercados de telecomunicações, indústria de computadores (softwares e hardwares), serviços com base em Internet (provedores de acesso e conteúdo) e outros equipamentos ou serviços que suportem esses mercados (POSNER, 2001), que não apresentam as características comumente encontradas nos mercados tradicionais.

Para Malerba (2003) com o surgimento da Internet, origina-se uma estrutura de mercado mais fluida com muitos atores diferentes com diferentes especializações e capacidades e novos tipos de usuários nos equipamentos e serviços de telecomunicações. Isso, por sua vez, expande os limites do setor criando novos segmentos e novas oportunidades e também na organização da inovação. Na próxima seção, será abordado o setor de jogos eletrônicos e suas plataformas, baseado na evolução tecnológica.

\section{2- INTERNET, JOGOS ELETRÔNICOS E SEUS ELEMENTOS}




\section{A INDÚSTRIA DOS JOGOS ELETRÔNICOS: NOVAS TECNOLOGIAS, PROPRIEDADE INTELECTUAL E CENÁRIO MUNDIAL E BRASILEIRO}

O surgimento da Internet gera mais pressão a favor de abrir padrões e leva ao surgimento de novos atores, como os provedores de conteúdo. A coevolução leva ao surgimento de novas atividades como um processo de fusão, como as tecnologias audiovisuais (CORROCHER \& MALERBA, 2002).

Em relação ao setor de jogos eletrônicos, uma pesquisa da InsideComm com a Associação Comercial e Cultural de Games (Acigames) revelou que as categorias de jogos eletrônicos jogados em consoles, ainda lideram na preferência do jogador brasileiro, seguido pelos computadores e depois a tecnologia mobile ${ }^{6}$. No entanto, é esperado que em alguns anos a mídia móvel ultrapasse os consoles e se torne líder no mercado de jogos, tendência que começa a acontecer com a disponibilização de jogos inovadores para smartphones ${ }^{7} \mathrm{e}$ expansão da internet.

Nesta seara, registra-se que o setor de jogos eletrônicos cada vez mais relacionado com a internet e dependentes da P\&D e I mais complexas e transversais. Deste modo, os avanços tecnológicos contribuem para alterar o segmento de jogos eletrônicos, seus modelos de negócios, sua audiência e sua visibilidade. A ampliação do poder de processamento dos hardwares, o aumento da capacidade gráfica, a expansão da internet, a banda larga móvel, e os smartphones expandiram significativamente o mercado, permitindo o surgimento de jogos online, que interconectam pessoas no mundo todo. Esses avanços modificaram também os modelos de negócio, criando diversas possibilidades de geração de receita, através de publicidade, venda de acessórios virtuais e opções avançadas.

Verifica-se que os jogos eletrônicos possuem duas partes individualizáveis em categorias distintas. Uma primeira diz respeito aos elementos audiovisuais, tais como imagens (fixas ou em movimento), sons, trilha sonora, cenários, personagens, roteiro, argumento, narrativa, dentre outros. A segunda se refere ao software, que tecnicamente gere os elementos audiovisuais e permite aos usuários interagir com os diferentes elementos do jogo. Neste sentido, de acordo com a Lipson e $\operatorname{Brain}^{8}$, os jogos eletrônicos possuem os seguintes elementos criativos:

${ }^{6}$ https://www.ecommercebrasil.com.br/noticias/industria-de-jogos-eletronicos-um-setor-em-ascensao-no-brasil/ Acesso em $02 / 10 / 2017$.

${ }^{7}$ https://www.ecommercebrasil.com.br/noticias/industria-de-jogos-eletronicos-um-setor-em-ascensao-no-brasil/_ Acesso em 02/10/2017.

8 Lipson, Ashley Saunders e Brain, Robert D., Computer and Video Game Law - Cases, Statutes, Forms, Problems \& Materials, Carolina Academic Press, 2009, p. 54. 
I. Elementos de áudio:1. composições musicais, 2. Gravações Sonoras, 3. Voz, 4. Efeitos sonoros importados, e 5. Efeitos sonoros internos.

II. Elementos de vídeo:1. Imagens fotográficas (P.E., Giff, TIFF, JPEG); 2. Digital Captura Imagens em Movimento (P.E., Mpeg);3. Animação;4. Texto

III. Código de computador (Código Fonte): 1. Engenharia primária do jogo (Primary Game Engine or Engines);2. Código primário (Ancillary Code);3. Plug-Ins (sub-rotinas de Terceiros); e 4. Comentários (Comments).

Além disso, o mercado de plataformas (consoles, PCs, jogos online) tem evoluído com a demanda de diversos tipos de jogos, contribuindo também à evolução das profissões relacionadas aos jogos. Podemos listar os seguintes possíveis profissionais atuantes: (i) o produtor, que supervisiona o trabalho de todos os envolvidos na criação do jogo de vídeo; (ii) coordenador de produção; (iii) produtor assistente; (iv) produtor associado; (v) diretor de produção; (vi) designers de jogos; (vii) diretor criativo; (ix) escritor; (x) roteirista; (xi) artista, o criador da arte visual do jogo; (xii) programador ou engenheiro, que cria e adapta o código do jogo de vídeo; e (xiii) designer de áudio, responsável pela criação de efeitos sonoros e outros elementos sonoros relacionados; bem como outras profissões não criativas como a do publisher, responsável pela manufaturação e marketing do jogo (ativos complementares).

É importante considerar que estes profissionais podem deter direitos autorais dependendo da sua contribuição para o trabalho. Em geral, a fim de ser titular de direitos autorais, é preciso desenvolver elementos originais e criativos ou executar o trabalho de outro criador (por exemplo, atores, músicos). Na maioria dos casos, esses autores têm uma relação celetista com a empresa de desenvolvimento, de modo que os direitos sobre as obras são retidos pelo empregador. No entanto, se o trabalho não é criado dentro desta relação, o produtor deve garantir a transferência adequada dos direitos, a fim de publicar e comercializar o jogo eletrônico de forma adequada.

Já a segunda parte dos jogos se concentra no elemento de programação, o software, o qual é a forma como os elementos audiovisuais são tecnicamente gerenciados e colocados à disposição do usuário através dos meios de interação disponíveis.

Assim, os jogos também podem receber proteção como programa de computador, devido ao fato que os processos de desenvolvimento e algoritmos utilizados são únicos, inovadores e criativos, e sua proteção é essencial nos termos da legislação de software. 
Ademais, há julgados (especialmente nos processos criminais) que classificam os jogos como software ou programa de computadores ${ }^{9}$.

Portanto, os jogos eletrônicos são obras complexas de autoria - contendo formas múltiplas de arte, tais como música, roteiro, gráficos, e personagens - que envolvem a interação humana ao executar o jogo com um programa de computador em um hardware específico. Os elementos dos jogos eletrônicos contribuem à escolha o modelo de negócios para este setor. Na próxima seção, aborda-se o papel da PI no setor de jogos eletrônicos.

\section{3- JOGOS ELETRÔNICOS E PROPRIEDADE INTELECTUAL}

Os jogos eletrônicos incluem numerosas formas de expressão e, consequentemente permeiam por uma discussão sobre a sua tutela jurídica, devido à sua natureza complexa e transversal, uma vez que apresentam uma série de questões e desafios em termos de propriedade intelectual.

$\mathrm{O}$ atual cenário internacional de proteção legal dos jogos eletrônicos parece extremamente complexo (OMPI, 2013). Embora o artigo $2^{\circ}$ da Convenção de Berna para a Proteção das Obras Literárias e Artísticas, de 9 de setembro de 1886, revista em Paris, a 24 de julho de 1971 (Decreto $n^{\circ} 75.699$, de 06 de maio de 1975) constitua uma base sólida para a elegibilidade para a proteção de games por direitos autorais, eles são de fato obras complexas de autoria, potencialmente compostas por múltiplas obras protegidas por direitos autorais.

Conforme mencionado anteriormente, os jogos eletrônicos contêm pelo menos duas partes principais: elementos audiovisuais (incluindo imagens, gravações de vídeo e sons); e o software (programa de computador), que administra tecnicamente os elementos audiovisuais e permite aos usuários interagir com os diferentes elementos do jogo.

Como resultado, as questões relacionadas ao regime legal aplicável aos jogos eletrônicos não possuem respostas óbvias. Para alguns países, os jogos eletrônicos são predominantemente programas de computador, devido à natureza específica das obras e à sua dependência de software. Enquanto em outras jurisdições, a complexidade dos jogos eletrônicos implica que eles recebem uma classificação distributiva. Finalmente, poucos países consideram que os jogos eletrônicos são essencialmente trabalhos audiovisuais

${ }^{9}$ Diário de Justiça do Estado de São Paulo DJSP de 07/01/2011, p. 193, processo no 9110445-88.2007.8.26.0000. 
(OMPI, 2013).

Deste modo, a maioria das jurisdições tende a proteger essas obras de autoria como programa de computador; uma vez que praticamente o único elemento comum de cada game é o seu programa de computador subjacente. No entanto, considerando os últimos desenvolvimentos em tecnologia, é importante enfatizar que, em muitos casos, diferentes jogos irão compartilhar códigos-fonte similares quando desenvolvidos usando o mesmo software (OMPI, 2013). Este elemento deve ser levado em consideração ao analisar a natureza jurídica dos games.

Embora a tendência majoritária considere que o software é o elemento predominante dos games, verifica-se que o elemento distintivo de um jogo eletrônico de outro não é apenas o software subjacente, mas também os vários elementos audiovisuais e literários criados para cada game, que também pode incluir performances de atores e músicos, com proteção por direitos autorais.

Nesta seara, verifica-se que não existe uma classificação explícita para jogos eletrônicos nos termos da legislação brasileira, assim há a opção por um regime no qual é possível a proteção nestas duas esferas (direito autoral e programa de computador) ${ }^{10}$. Neste sentido, os elementos audiovisuais dos jogos eletrônicos podem ser enquadrados na definição da Lei de Direito Autoral de obra audiovisual (art. 5º, VIII, “i” da Lei 9.610/1996) ${ }^{11}$ e o programa de computador seria protegido pela Lei ${ }^{\circ}$ 9.279, de 14 de maio de 1996.

Além disso, verifica-se que certos aspectos dos jogos eletrônicos também podem ser protegidos como segredos comerciais. Informação e processos criativos que envolvem o negócio e que têm valor econômico (por exemplo, listas de clientes, técnicas de fabricação e outras ferramentas) podem ser protegidos legalmente contra a apropriação indevida por terceiro. Para a proteção ser concedida, é necessário que haja razoável precaução pelos proprietários e desenvolvedores no sentido de controlar o acesso à informação, devendo empregados e outras pessoas envolvidas assinar acordos de não divulgação ou marcar os documentos com avisos de informação confidencial.

\footnotetext{
10 "The Legal Status of Video Games: Comparative Analysis in National Approaches", uma pesquisa realizada por Andy Ramos, Laura López, Anxo Rodríguez, Tim Meng e Stan Abrams para a Organização Mundial da Propriedade Intelectual - OMPI.

11 “VIII - obra:(...) i) audiovisual - a que resulta da fixação de imagens com ou sem som, que tenha a finalidade de criar, por meio de sua reprodução, a impressão de movimento, independentemente dos processos de sua captação, do suporte usado inicial ou posteriormente para fixa-lo, bem como dos meios utilizados para sua veiculação".
} 
Ademais, os jogos também podem incluir marcas, nomes comerciais e logotipos, todos estes protegidos pela Lei $n^{\circ}$ 9.279, de 14 de maio de 1996. Este tipo de proteção (registro da marca) é importante, a fim de evitar a apropriação indevida de marcas de terceiros, que pode confundir os consumidores quanto à origem do produto.

Considerando o tamanho do mercado e sua diversidade, torna-se necessário discutir a forma de proteção dos jogos eletrônicos, assim com a organização dos direitos detidos por cada um dos agentes de mercado. Assumindo-se como premissa que a natureza dos produtos e dos serviços circulados no mercado de jogos eletrônicos é imaterial, a estrutura jurídica apta a governar as relações encontra-se em grande medida no âmbito do ramo da propriedade intelectual. Deste modo, verifica-se o papel fundamental da propriedade intelectual no setor de jogos eletrônicos, que pode ser utilizado como um dos elementos no processo de apropriabilidade.

Ademais, o nível de complexidade cresce significativamente devido ao fato de que, nos últimos anos, o mercado de games continua a evoluir exponencialmente (OMPI, 2013). Como consequência, para o desenvolvimento dos jogos eletrônicos, cada vez mais se utiliza um número maior de agentes envolvidos na criação destas obras.

Neste sentido, para a produção dos jogos eletrônicos, utilizam-se de atividades criativas e técnicas, que demandam novas tecnologias, responsáveis pela geração de novos produtos e serviços, que impactam para atividades em outras empresas e organizações dentro e fora do setor. Dessa forma, produz externalidades para o conjunto da Economia.

Deste modo, na próxima seção será analisado o cenário mundial e brasileiro da indústria de jogos eletrônicos, considerando o crescimento considerável do valor do mercado mundial de jogos eletrônicos nos últimos anos. Ademais, os jogos eletrônicos possibilitam a difusão de cultura, além de funcionar como propulsor de desenvolvimento tecnológico e de dinamização de atividades correlatas e afins, como design, programação, telecomunicações e realidades aumentada e virtual. Na próxima seção, será abordado o setor de jogos no Brasil e no mundo.

\section{4- CENÁRIO MUNDIAL E BRASILEIRO DOS JOGOS ELETRÔNICOS}

A indústria de jogos eletrônicos está atingindo um status maduro (Tschang, 2007), e é, juntamente com as indústrias de software e biotecnologia, considerada uma nova indústria economicamente relevante (OCDE, 2005). A PricewaterhouseCoopers prevê que os jogos 
eletrônicos serão a mídia de crescimento mais rápido nos próximos anos, sendo que as empresas de alto desempenho em games em termos de volume de negócios e inovação são empresas americanas e japonesas (STORZ ET AL, 2014).

Em 2015, a indústria de jogos eletrônicos movimentou USD\$ 91,5 bilhões (NEWZOO, 2016). As grandes empresas do mercado foram responsáveis por 67\% (sessenta e sete por cento) desta receita e atingiram $14 \%$ (quatorze por cento) na taxa anual de crescimento. China, Estados Unidos, Japão e Coréia do Sul permanecem na liderança do setor. O Brasil se encontra na décima primeira posição, em que auferiu USD\$ 1,46 bilhão em 2014. Dentro da América Latina, o Brasil lidera o ranking deste setor seguido por México e Argentina.

A indústria de jogos eletrônicos promove inovação tecnológica e impulsiona o desenvolvimento de outros segmentos de mercado. Em sua etapa de produção, os jogos combinam a aplicação de conhecimento tecnológico e científico, bem como atividades de pesquisa e expressões artísticas. A indústria demanda recursos humanos qualificados para formação de equipes multidisciplinares capazes de gerar produtos competitivos e inovadores.

Além da perspectiva econômica, os jogos eletrônicos, sobretudo os jogos online, ocupam um espaço cada vez mais significativo na vida das pessoas, pois eles também introduziram uma nova forma de comunicação entre as pessoas, influenciando assim a sociedade e a cultura.

Fator que impulsionou os jogos eletrônicos foi a conectividade. Ademais, a expansão das redes sociais dos últimos anos intensifica o processo de crescimento dos jogos online. $\mathrm{O}$ Facebook tem se mostrado como exemplo do modo pelo qual as redes sociais têm apresentado os jogos eletrônicos aos jogadores casuais.

Isso se repercute no aumento da publicidade dos jogos nesse meio, como pode ser visto no gráfico a seguir. O “click-through rate - CTR" 12 cresceu significativamente de 2013 para 2014, o que confirma a efetividade desta rede social (Facebook) na propagação dos jogos online, conforme o gráfico 1.

\footnotetext{
12 Click-through rate - CTR é a razão de usuários que clicam em um link específico sobre o número total de usuários que acessaram determinada página. Por isso, o CTR é considerado uma medida de sucesso da publicidade online de determinada campanha. Cost per click - CPC é o valor pago pelo anunciante para cada clique efetuado em sua publicidade. Cost per thousand - CPM é o valor pago pelo anunciante para cada 1.000 (mil) exibições de sua publicidade.
} 
Gráfico 1

Métrica do Custo de Publicidade para Jogos Eletrônicos do Facebook no Mundo, no terceiro trimestre de 2013 e de 2014

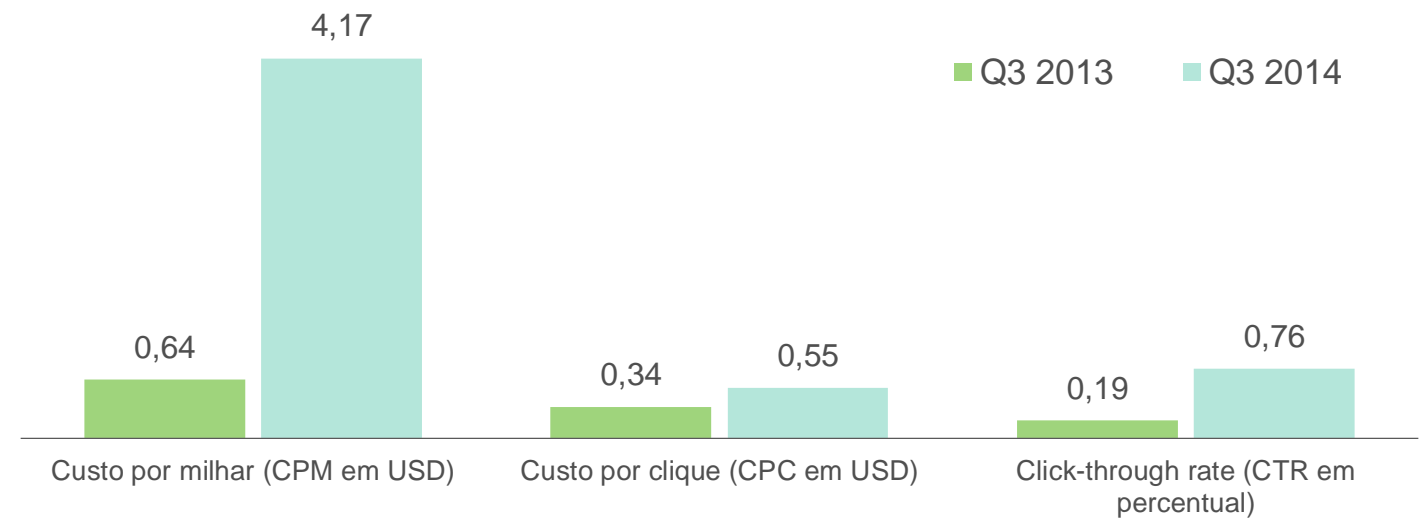

Fonte: Nanigans. Global Facebook Advertising Benchmark Report (2014).

Ademais, conforme dados da Newzoo (2015), o mercado de jogos eletrônicos movimentou USD\$ 1,46 bilhões no Brasil em 2015, colocando-o na $11^{\mathrm{a}}$ posição no mundo e $4^{\mathrm{a}}$ posição no ranking mundial em quantidade de jogadores.

O setor também se profissionalizou com o surgimento de entidades, como a Associação Brasileira de Games (AbraGames) e a Associação Comercial, Industrial e Cultural dos Jogos Eletrônicos no Brasil (Acigames), com o início de envolvimento do governo e com o intercâmbio de conhecimento entre players nacionais e internacionais.

No entanto, considerados os dados do $1^{\circ}$ Censo da Indústria Brasileira de Jogos Digitais promovido pelo Grupo de Estudos e Desenvolvimento da Indústria de Games GEDIGames e pelo Núcleo de Política e Gestão Tecnológica - NPGT da Universidade de São Paulo - USP, verifica-se que o quadro dos agentes produtores no país ainda é incipiente.

A maioria das produtoras brasileiras $(74,40 \%)$ tem um faturamento anual de até $\mathrm{R} \$$ 240 mil; 21,60\%, entre R \$ 240 mil e R \$ 2,4 milhões, e os 4\% restantes, entre R \$ 2,4 milhões e R\$ 16 milhões ( $1^{\circ}$ Censo IBJD, 2014), o que representa uma pequena participação nas receitas do mercado mundial de jogos eletrônicos.

Faturamento das empresas brasileiras no ano de 2013

\begin{tabular}{lcr}
\hline \multicolumn{1}{c}{ Faturamento } & Empresas & $\%$ \\
\hline Até R\$ 240 mil & 93 & $74,4 \%$ \\
\hline $\begin{array}{l}\text { Entre R\$ } 240 \text { mil e R\$ } \\
\text { 2,4 milhões }\end{array}$ & 27 & $21,6 \%$ \\
\hline
\end{tabular}




Entre R\$2,4 milhões e
$\mathrm{R} \$ 16$ milhões

Fonte: $1^{\circ}$ Censo IBJD (2014)

\section{Gráfico 3}

Número de empresas desenvolvedoras de jogos eletrônicos por faturamento (R \$) no ano de 2013 -fonte $1^{\circ}$ Censo IBJD (2014)

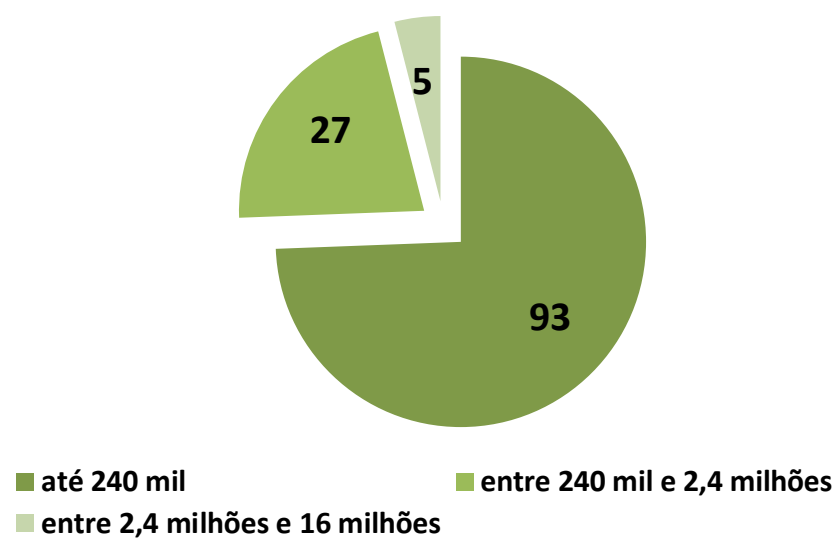

Observa-se que a indústria brasileira necessita de desenvolvimento para se tornar competitiva no mercado global. Verifica-se ainda que a maioria das empresas pode ser considerada de pequeno porte: micro e pequenas empresas. Assim, os desenvolvedores de jogos são de pequeno porte e tem reduzida participação na produção de jogos eletrônicos no mercado internacional.

Assim, o cenário nacional possui produtores de pequeno porte, ainda com pouca experiência, poucos recursos humanos e baixa capitalização. Deste modo, a atividade de produção dos possui um grau de maturidade baixo. Além disso, ainda há pouco investimento na formação profissional e técnica de profissionais neste setor, conforme dados do $1^{\circ}$ Censo da Indústria Brasileira de Jogos Digitais.

Deste modo, verifica-se a necessidade de uma política setorial, que abarque as necessidades da indústria de jogos eletrônicos nacional, aos moldes do que é feito em diversos países do mundo. Nesse sentido, entende-se como necessidades, além do fomento para produção de games nacionais através de editais públicos para produção ou desenvolvimento de protótipo (englobando planos de negócios), o estímulo à capacitação de recursos humanos e à retenção dos mesmos em território nacional.

Ademais, é importante incentivar a gestão da propriedade intelectual sobretudo para 


\section{A INDÚSTRIA DOS JOGOS ELETRÔNICOS: NOVAS TECNOLOGIAS, PROPRIEDADE INTELECTUAL E CENÁRIO MUNDIAL E BRASILEIRO}

o setor de jogos eletrônicos, tendo em vista que os games são obras de complexa autoria, que podem possuir elementos audiovisuais, além do programa de computador. Destaca-se por não ter uma legislação específica no Brasil sobre a natureza jurídica dos jogos eletrônicos, a propriedade intelectual pode ser utilizada estrategicamente pelas empresas como a finalidade de maior aproveitamento financeiro.

Cabe destacar ainda que são relevantes investimentos em outras as áreas do setor, como gestão empresarial e marketing (entre outros ativos complementares), pois conforme visto na seção anterior, a difusão de inovações depende da capacitação dos agentes, da infraestrutura adequada para a assimilação tecnológica, e de tempo para aprender a dominar novas tecnologias, já que o uso dos métodos de apropriabilidade varia de acordo com os setores, especificidades tecnológicas e dependem do comportamento estratégico das empresas.

\section{CONCLUSÃO}

A globalização da inovação não é um fenômeno único, mas um conceito abrangente para descrever uma ampla gama de forças. A tentativa de estimar seu peso de acordo com a localização geográfica e os setores industriais mostra que a importância das forças globais na inovação está aumentando rapidamente.

Analisou-se que os meios de apropriabilidade devem se posicionar em diversos segmentos, proporcionando meios jurídicos, tributários, econômicos, intelectuais e financeiros favoráveis para a evolução de toda a cadeia. Neste sentido, analisou-se ainda a contribuição de inovação tecnológica quanto às implicações para a escolha do modelo de negócios das empresas, que pode variar a depender do setor e do país a que pertencem em razão da especificidade da natureza do conhecimento utilizado.

Assim, com o surgimento de novas tecnologias, em especial a ampliação do poder de processamento dos hardwares, o aumento da capacidade gráfica, a expansão da internet, a banda larga móvel, e os smartphones, origina-se uma estrutura de mercado mais fluida com atores diferentes, com diversas especializações, capacidades, e novos tipos de usuários nos equipamentos e serviços de telecomunicações. Ademais, a expansão da Internet gera mais pressão a favor de abrir padrões e leva ao surgimento de novos atores, como os provedores de conteúdo. 
Neste sentido, verificou-se que atualmente o setor dos jogos eletrônicos é um dos segmentos da indústria do entretenimento que mais cresce no mundo. Os dados sobre a indústria de jogos eletrônicos demonstram que o Brasil está entre um dos maiores mercados de jogos eletrônicos no mundo. Apesar disto, verificou-se que este setor no país ainda se encontra em um estágio iniciante, necessitando atingir maior grau de desenvolvimento para se tornar competitivo.

Registrou-se que os jogos eletrônicos são obras complexas de autoria, uma vez que possuem formas múltiplas de arte como: música, roteiro, gráficos, e personagens, que envolvem a interação humana ao executar o jogo com um programa de computador em um hardware específico. Assim, os jogos eletrônicos são criados como um conjunto de elementos, em que cada um deles pode ser individualmente objeto de propriedade intelectual (isto é, sua trilha sonora, personagens, argumento, programa de computador, etc.).

Verificou-se, portanto, que a proteção jurídica sobre os jogos eletrônicos se situa na fronteira entre a obra audiovisual, protegida através do direito autoral, e o software, protegido em regime específico, este com princípios afetos ao direito autoral, mas ao mesmo tempo com particularidades (Lei $n^{\circ}$ 9.609/98). Diversos regimes jurídicos estrangeiros estabeleceram soluções autônomas para esta questão, com base na OMPI (2013).

Destacou-se a análise dos principais tópicos e questionamentos envolvendo jogos eletrônicos no tocante à propriedade intelectual a serem levados em consideração, em especial a síntese esquematizada acerca da possibilidade da natureza e respectiva proteção legal dos jogos eletrônicos.

As respostas às perguntas sobre proteção legal dos jogos eletrônicos podem ser diferentes das aplicáveis há vinte anos. É claro que à medida que a indústria continua sua evolução estável, as soluções para proteção legal dos games podem continuar a variar nos próximos anos.

Por fim, entende-se que, para o setor de jogos eletrônicos, devem ser considerados, mecanismos como as estratégias de negócios, em especial a propriedade intelectual, para possibilitar o crescimento deste segmento no país. Ademais, as políticas públicas voltadas à indústria de jogos são aconselháveis em capacitação dos agentes, fomento e modelo de negócios.

\section{REFERÊNCIAS}


ABRÃO, Eliane Yachouh. Considerações em torno do Direito Autoral no Mundo Digital. In: VALLE, Regina Ribeiro do (org.). E-dicas: O Direito na Sociedade da Informação. São Paulo: Usina do Livro, 2005.

. Direitos de autor e direitos conexos. São Paulo: Editora do Brasil, 2002.

AGÊNCIA NACIONAL DO CINEMA - ANCINE. Análise de Impacto Regulatório AIR - Jogos eletrônicos. https://www.ancine.gov.br/sites/default/files/consultaspublicas/AIR-JogosEletronicos_0.pdf. Acesso em 10/05/2017.

AL-AALI, A. Y.; TEECE, D. J. (2013). Towards the (Strategic) Management of Intellectual Property: retrospective and prospective. California Management Review, 55(4).

ARCHIBUGUI, D.; IAMMARINO, S. (2002), The Globalisation of Technological Innovation: Definition and Evidence, Review of International Political Economy, vol. 9, no 1, p. 98-122.

BARBOSA, Denis Borges. Introdução à Propriedade Intelectual. 2 Ed. Rio de Janeiro: Lúmen Júris, 2003.

. Uma introdução à propriedade intelectual. $2^{\mathrm{a}}$ ed. Rio de Janeiro: Lumen Juris, 2010.Disponível em: 〈http://www.denisbarbosa.addr.com/arquivos/livros/umaintro2.pdf>.

BNDES. USP. GEDIGAMES. Mapeamento da Indústria Brasileira e Global de Jogos Digitais. São Paulo, 2014.

BRASIL. Constituição da República Federativa do Brasil: promulgada em 5 de outubro de 1988.

CARNEIRO, Ana Maria. Proteção de ativos na indústria de software: estratégias e tendências de propriedade intelectual. Campinas, SP: [s.n.], 2007.

CARVAlHEIRO, J. dos S. A concepção de autor em Bakhtin, Barthes e Foucault. Signum: Estudos de Linguagem. Volume 11, número 2. Londrina: Universidade Estadual de Londrina, 2008.

DOSI, G. Technological paradigms and technological trajectories: A suggested interpretation of the determinants and directions of technical change. In: Research Policy, vol. 11, p. 147162, 1982. (Versão em português no livro "Mudança técnica e transformação industrial", capítulo 2, item 2.2, Giovanni Dosi, coleção Clássicos da Inovação).

FREEMAN, C. “The 'National System of Innovation' in historical perspectives". Cambridge Journal of Economics, vol. 19, nº 1. Cambridge, 1995.

FREEMAN, Christopher \& PEREZ, Carlota. Structural crisis of adjustment, business cycles and investiment behaviour. In: DOSI, G. et alii (eds.) Technical Change and Economic Theory. London: Pinter Publishers, 1988.

GIDDENS, A. (1990) Consequences of Modernity, Cambridge: Polity Press.

HEILBRONER, Robert. A história do pensamento econômico. São Paulo: Editora Nova Cultural, 1996. (cap. II).

JÚNIOR, J. de O. P.; Educação e jogos eletrônicos: estudo de caso dos games produzidos com financiamento da FINEP. In: IX SBGames, Florianópolis, 2010. 
LEIPONENA, A; BYMA, J. If you cannot block, you better run: Small firms, cooperative innovation, and appropriation strategies. In: Research Policy, 38, 14781488,2009 .

LIPSON, Ashley, SAUNDERS e BRAIN, Robert D., Computer and Video Game Law Cases, Statutes, Forms, Problems \& Materials, Carolina Academic Press, 2009.

LUNDVALL, B.A. National innovation systems - analytical concept and development tool. Industry and Innovation, vol.14, $\mathrm{n}^{\circ}$ 1, p. 95119, 2007.

MALERBA, F. Sectorial Systems and Innovation and Technology Policy. Revista Brasileira de Inovação Volume 2 Número 2 Julho/Dezembro 2003.

MENDES, C.I.C. Software Livre e Inovação Tecnológica: uma Análise sob a Perspectiva da Propriedade Intelectual. Dissertação (mestrado). Instituto de Economia, Universidade Estadual de Campinas - Unicamp. Campinas: 2006.

NIGRI, Deborah Fisch. Direito Autoral e a Convergência de Mídias - Cadernos de Direito da Internet, vol. II. Rio de Janeiro: Editora Lumen Juris, 2006.

OCDE, 2005. Digital Broadband Content: The online computer and video game industry. Working Party on the Information Economy. OECD Publishing, Paris, Disponível em: http://www.oecd.org/dataoecd/19/5/34884414.pdf.

OLI, João Carlos De Camargo. Pequeno Mosaico do Direito Autoral. Rio de Janeiro: Irmãos Vitale, 2006.

ORGANIZAÇÃO MUNDIAL DA PROPRIEDADE INTELECTUAL - OMPI.

PAESANI, Liliana Minardi. Direito e Internet: liberdade de informação, privacidade e responsabilidade civil. 3. ed. São Paulo: Atlas, 2006.

PATEL, P.; PAVITT, K. National systems of innovation under strain: the internationalisation of corporate R\&D. [S. 1.] : Science Policy Research Unit. University of Sussex, 1998. (Eletronic Working Papers Series, n. 22). Disponível em: <http://www. Sussex.ac.uk/spru>

PAVITT, K. Sectoral patterns of technical change: towards a taxonomy and a theory. Research Policy, [Amsterdam], Netherlands, v. 13, n. 6, p.343-373, 1984.

PEREZ, C. Technological revolutions and techno-economic paradigms, Working Papers in Technology Governance and Economic Dynamics The Other Canon Foundation, Norway and Tallinn University of Technology, Tallinn, 2009. Disponível em: <http://e-tcs.org/wpcontent/uploads/2012/04/PEREZ-Carlota-Technological-revolutions-and-techno-

economic-paradigms1.pdf $>$.

POSNER, Richard A. Antitrust law. $2^{\text {a }}$ edição. Chicago: The University of Chicago Press, 2001.

Intellectual Property: The Law and Economics Approach. In: Journal of Economic Perspective, vol. 19, nr 2, 2005.

PISANO, G. Profiting from innovation and the intellectual property revolution. In: Research Policy, 35, 1122-1130, 2006.

RABIN, S. (Ed) Introdução ao Desenvolvimento de Games, volume 4 São Paulo: Cengage learning, 2013. 
RAMOS, A., LÓPEZ, L., RODRIGUEZ, A., MENG, T.; e ABRAMS, S., “The Legal Status of Video Games: Comparative Analysis in National Approaches”, uma pesquisa para a Organização Mundial da Propriedade Intelectual - OMPI, 2013.

ROVER, Aires José; WINTER, Djônata. A Revolução Tecnológica Digital e a Proteção da Propriedade Intelectual. In: WACHOWICZ, Marcos (coord.). Propriedade Intelectual \& Internet: uma perspectiva integrada à Sociedade da Informação. Tradução Omar Kaminski. Curitiba: Juruá Editora, 2002.

STORZ, C. Japan's innovation system and "cool" industries: What does game software case teach us? 2002. Disponível em: < http://www.jil.go.jp/profile/documents/Storz.pdf>.

Dynamics in innovation systems: Evidence from Japan's game software industry. In: Research Policy, 2008.

STORZ, C., RIBOLDAZZI, F., JOHNA, M. Mobility and innovation: A cross-country comparison in the video games industry. In: Research Policy, 2014.

TEECE, D. J. Profiting from technological innovation: implications for integration, collaboration, licensing and public policy. In: Research Policy, 1986.

TERUYA, D. Y. Panorama do Direito da Propriedade Industrial na América Latina. Cadernos Prolam/USP 13 (25): p. 95-116, 2014.

TIGRE, P. B, Gestão da inovação: a economia da tecnologia do Brasil. Rio de Janeiro. Elsevier, 2006.

TSCHANG, F., 2007. Balancing the Tensions between Rationalisation and Creativity in the Video games Industry. Organization Science 18 (6), 989-1005.

QUERETTE, E.; ClUA, E.; TIGRE, P. B.; ARAÚJO, S. V. A. Políticas públicas para a indústria de games: uma agenda para o Brasil. In: XI SBGames, 2012, Brasília.

VIDE, Carlos Rogel. Manual de direito autoral. Rio de Janeiro, Lumen Juris, 2010.

ZUCOLOTO, G. Apropriabilidade tecnológica e desempenho exportador das firmas brasileiras. $41^{\circ}$ Encontro Nacional de Economia (ANPEC), Foz do Iguaçu, 2013. 